\title{
Biomarkers of endothelial function and insulin resistance response to aerobic exercise versus resisted exercises in obese type 2 diabetic patients
}

\author{
Shehab M. Abd El-Kader*1 and Fadwa M Al-Shreef ${ }^{2}$ \\ ${ }^{1}$ Department of Physical Therapy, Faculty of Applied Medical Sciences, King Abdulaziz University, Saudi Arabia \\ ${ }^{2}$ Department of Medical Laboratory Technology, Faculty of Applied Medical Sciences, King Abdulaziz University, Saudi Arabia
}

\begin{abstract}
Background: The risk of endothelial dysfunction and insulin resistance is higher in type 2 diabetes mellitus which could be modulated with exercise training. However, to our knowledge, there is no clinical studies have addressed which exercise specific type is superior in modulating biomarkers of endothelial dysfunction and insulin resistance for type 2 diabetes mellitus (T2DM).
\end{abstract}

Objective: This study aimed to determine the differences in response of biomarkers of endothelial dysfunction and insulin resistance to aerobic versus resistance exercises in type 2 diabetic patients. Material and methods: Eighty obese type 2 diabetic patients participated in this study and were included into two groups, group (A) received aerobic exercises; where group (B) received resistance exercises for 12 months.

Results: The mean values of Inter-Cellular Adhesion Molecule (ICAM-1), Vascular Cell Adhesion Molecule (VCAM-1), tissue plasminogen activator (tPA), E-selectin, glycosylated hemoglobin (HBA1c) and Homeostasis Model Assessment-Insulin Resistance (HOMA-IR) were significantly decreased in both groups at the end of the study. However, the mean values of ICAM-1, VCAM-1 and tPA:Ag were more significantly reduced in group (A), while the mean values of HBA1c and HOMA-IR were more significantly reduced in group (B) and there were significant differences between both groups at the end of the study.

Conclusion: Based on our findings, resistance exercise appears to be more beneficial than aerobic exercise for improving insulin resistance in type 2 diabetes mellitus. Also, aerobic exercise appears to be more beneficial than resistance exercise for improving endothelial function in type 2 diabetes mellitus.

\section{Introduction}

Over the previous 2 decades, type 2 diabetes mellitus becomes a major health problem as globally about 366 million were affected in 2011 and it is expected to have 552 million of type 2 diabetes mellitus in 2030 [1]. Globally, type 2 diabetes mellitus is considered a major chronic disorder leads to morbidity and mortality $[2,3]$. However, the risk of obesity and type 2 diabetes mellitus is progressively increased and as a result the risk of insulin resistance, coagulation disorders, dyslipidemia and the cardiovascular complications [4,5] which considered the principal causes for the overall morbidity and mortality in obese diabetic subjects [6].

The endothelial dysfunction usually comes before the development of cardiovascular disorders [7], so early detection and correction of endothelial dysfunction should be done for appropriate prevention of atherosclerosis and as result cardiovascular disorders development $[8,9]$. Aerobic exercise may enhance the endothelial function in obsess non-insulin dependent diabetes mellitus [10]. Moreover, endothelial dysfunction was reversed by application of moderate intensity aerobic exercise for 60 minutes/ day for seven weeks in type 2 diabetic $\mathrm{db} / \mathrm{db}$ mice [11].

There are many laboratory markers to measure the markers of endothelial dysfunction and increased levels of this biomarker indicate increased risk of cardiovascular diseases [12,13]. Moreover, higher serum level of tissue plasminogen activator (tPA) is an indicator of activation of endothelial activities associated with increased risk of cardiovascular dysfunction [14].

Insulin resistance has a major role in increased risk of atherosclerosis and other cardiovascular disorders in type 2 diabetic patients [15]. However, aerobic exercise modifies the metabolic risk factors for cardiovascular dysfunction through improving of insulin sensitivity [16-18].

Resistance exercise training Resisted exercise training displayed many health benefits as increasing glucose uptake and insulin sensitivity by skeletal muscles $[19,20]$. Moreover, resisted exercise training modulates blood lipids profile disorders [21]. However, recent studies documented the common benefits of both aerobic and resisted exercise training for cardiovascular disorders [22].

As it is less clear which is more beneficial aerobic or resistance exercise training for modulation of endothelial function and insulin

Correspondence to: Shehab M Abd El-Kader, Department of Physical Therapy, Faculty of Applied Medical Sciences, King Abdulaziz University, P.O. Box 80324, Jeddah, 21589, Saudi Arabia, Tel: +966-569849276; E-mail: profshehab@live.com

Key words: aerobic exercise, endothelial function biomarkers, insulin resistance, obesity, resistance training, Type 2 diabetes mellitus

Received: February 17, 2017; Accepted: March 14, 2017; Published: March 17, 2017 
resistance. So, the present study aims to compare impact of aerobic and resistance exercises on insulin resistance and markers of endothelial function in type 2 diabetic obese patients.

\section{Patients and methods}

\section{Subjects}

Eighty patients with type 2 diabetes mellitus, of both genders, aged between 40 and 55 years, without coronary arterial disease who visited the out clinic of diabetes at King Abdalaziz University Hospital, Saudi Arabia. All the participants were informed regarding the objectives of the study and about the possible risks and discomforts involved with their participation in the experiments, signed an informed consent. The exclusion criteria included subjects receiving medicines with known effect on endothelial function, as angiotensin converting enzyme inhibitors, calcium channels blockers, nitrates, beta-blockers, antioxidizers, hormonal replacement and insulin; cigarette smoking history in the last 12 months; participation in a physical exercise program in the last 12 months; chronic obstructive pulmonary disease; hypertension (systolic blood pressure above $180 \mathrm{mmHg}$ or diastolic blood pressure above $110 \mathrm{mmHg}$ ); osteoporosis and diabetic neuropathy, congestive heart failure, uncontrollable cardiac arrhythmias, and severe illness that precluded them from exercising.

A cardiologist conducts an initial clinical examination for all participants. However, initial rest electrocardiogram was made and the blood pressure was measured, also the electrocardiogram was continuously observed and the blood pressure was measured in each period. The participants were guided to keep the original dietary habits and behaviors. Also, participants were randomized for an aerobic exercise (group A) or resisted exercise (group B). The CONSORT diagram outlining the details of the screening, run-in and randomization phases of the study and reasons for participant exclusion can be found in Figure 1. Informed consent was obtained from all participants. This study was approved by the Scientific Research Ethical Committee, Faculty of Applied Medical Sciences at King Abdulaziz University.

\section{Measurements}

All subjects underwent a laboratory examination, performed at Laboratory of King Abdalaziz University Teaching Hospitals, after a $12 \mathrm{~h}$ period of fasting.

A. Measurement of glycosylated hemoglobin and insulin resistance: Blood sample after fasting for 12 hours was taken from each patient in clean tubes containing few mg of K2EDTA, centrifuged

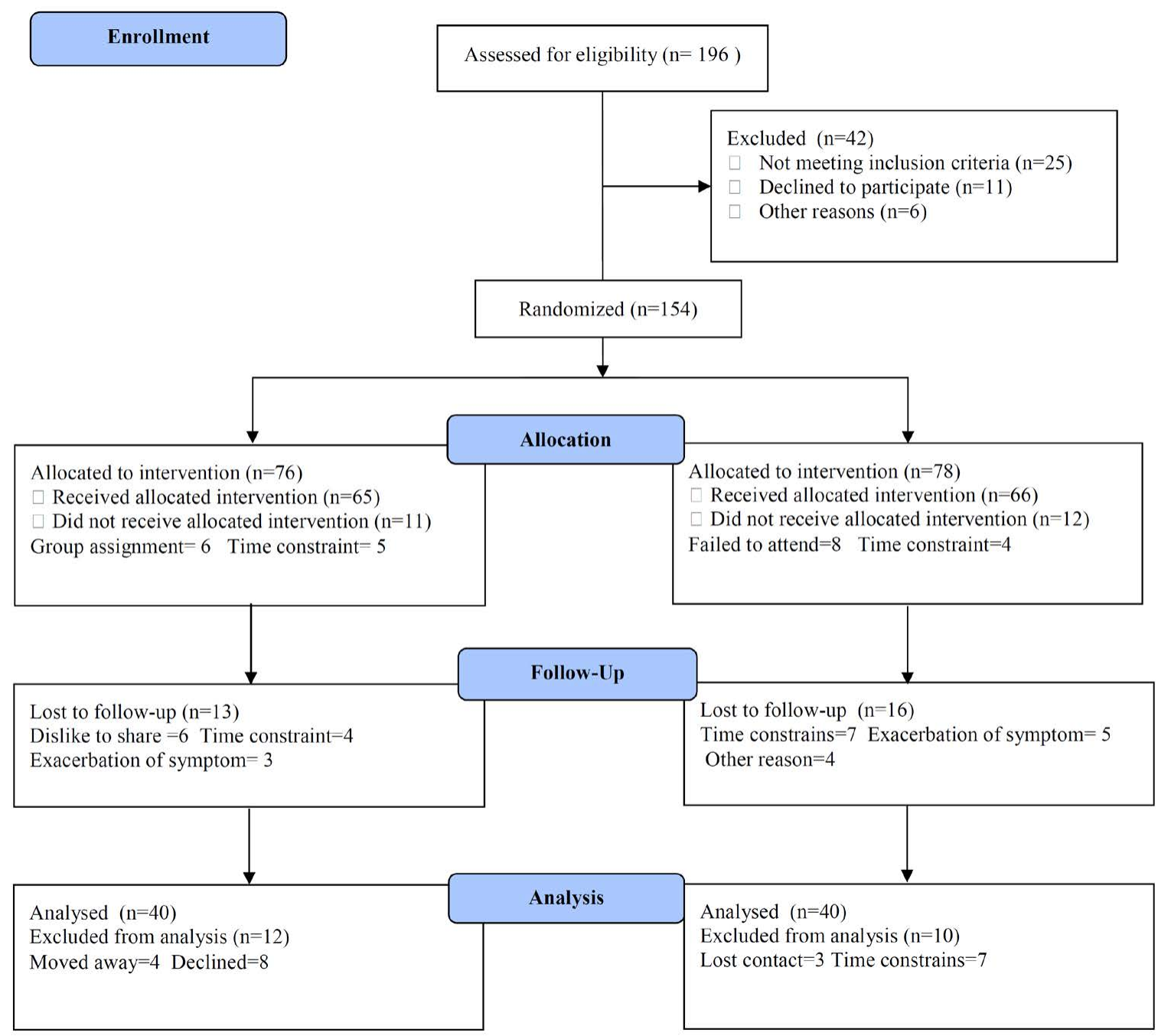

Figure 1. Subjects screening and recruitment CONSORT diagram. 
and plasma was separated and stored frozen at $-20^{\circ}$ used for estimation of glycosylated hemoglobin $\left(\mathrm{HBA}_{1} \mathrm{c}\right)$ using colorimetric method. Homeostasis Model Assessment-Insulin Resistance (HOMA) index for insulin sensitivity was computed following this equation: [fasting glycemia $(\mathrm{mmol} / \mathrm{L}) \cdot$ fasting insulin $(\mathrm{mIU} / \mathrm{L})] / 22.5[23]$.

B. Measurement of biomarkers of endothelial function: Adhesion molecules biomarker includes E-selectin, Inter-Cellular Adhesion Molecule (ICAM-1), Vascular Cell Adhesion Molecule (VCAM-1) and tissue plasminogen activator antigen (tPA:Ag) were measured from frozen serum samples stored at $-80^{\circ} \mathrm{C}$. Enzyme-linked immunosorbent assays (ELISAs) were used to measure soluble levels of E-selectin, ICAM-1and CAM-1 (R\&D Systems), however tissue plasminogen activator antigen (tPA:Ag) was determined using a commercial kit (Hyphen BioMed for t-PA, France).

All measurements were done at the beginning of the study and will be repeated after 3 months.

\section{Procedures}

Following the previous evaluation, all patients were divided randomly into the following groups:

A. Aerobic exercise: The aerobic exercise group completed a 12 -week aerobic exercise training program. Each session of physical exercise was divided in: 5 min of warm up, with stretching exercises and circling of members and body; 30 min of aerobic exercise divided into row ergometer $(15 \mathrm{~min})$ and bicycle ergometer (15 min).; and 5 min of cold down at the end, with stretching, flexibility and relaxation exercises, five sessions per week. The training program was performed at $70 \%$ of the individual age-predicted maximal heart rate $\left(\mathrm{HR}_{\max }\right)$ according to Tanaka et al. [24]. The exercise sessions were supervised by one of the investigators and the determined intensity of exercise was monitored and registered for each patient by a watch of heart rate (Polar Vantage XL, Polar Electro Inc., Port Washington, NY). The alarms of the watches were programmed for the inferior and superior limits of the correspondent intensity, determined for each patient.

B. Resistance exercise: The aerobic resistance group completed a 12-week of resistance exercise training program. Each session of physical exercise was divided in: 5 min of warm up, with stretching exercises and circling of members and body; $30 \mathrm{~min}$ of specific resistance training; and 5 min of cold down at the end, with stretching, flexibility and relaxation exercises, five sessions per week [25]. The resistance exercise protocol aimed to develop muscle mass and strength in the following muscle groups: (1) quadriceps (leg press and leg extension), (2) hamstrings (seated leg curl), (3) gluteal (hip abduction), (4) trunk and arms (double chest press, lateral raise and overhead press), and (5) abdominal wall (abdominal machine). Subjects exercised on variable resistance machines (Nautilus Sports/Medical Industries, Independence, VA). Training intensity was gradually increased during the first four weeks. The intensity of the training stimulus was initially set at $50 \%$ to $60 \%$ of one-repetition maximum (1RM) with a work range of two sets of 10 to 15 repetitions. Subjects then progressed from $65 \%$ to $75 \%$ of $1 \mathrm{RM}$ at a work range of six to eight repetitions (two sets) and remained at this level until the end of the program. 1RM tests were performed every two weeks for the first month and then every four weeks until the end of the program. Between these tests, the load was increased for those subjects who were able to easily complete 12 or more repetitions for both sets; The exercise sessions were supervised by one of the investigators and the determined intensity of exercise was monitored and registered for each patient by a watch of heart rate
(Polar Vantage XL, Polar Electro Inc., Port Washington, NY). The alarms of the watches were programmed for the inferior and superior limits of the correspondent intensity, determined for each patient.

\section{Statistical analysis}

The mean values of the investigated parameters obtained before and after three months in both groups were compared using paired " $\mathrm{t}$ " test. Independent " $t$ " test was used for the comparison between the two groups $(\mathrm{P}<0.05)$.

\section{Results}

Eighty patients with type 2 diabetes mellitus completed the screening evaluation. The baseline characteristics of the participants are shown in Table 1. Most participants (65\%) were men. Twenty five participants were assigned to the aerobic exercise intervention group $(\mathrm{n}=40 ; 26$ males and 14 females) and resistance exercise group $(\mathrm{n}=40$, 24 males and 16 females). None of the baseline characteristics differed significantly between the two groups is listed in Table 1 .

The mean values of ICAM-1, VCAM-1, tPA:Ag, E-selectin, HBA1c and HOMA-IR were significantly decreased in both groups at the end of the study (Tables 2 and 3). However, the mean values of ICAM-1, VCAM-1 and tPA:Ag were more significantly reduced in group (A), while the mean values of HBA1c and HOMA-IR were more significantly reduced in group (B) and there were significant differences between both groups at the end of the study (Table 4 ).

Table 1. Mean value of baseline characteristics of all participants.

\begin{tabular}{|l|l|l|l|}
\hline & Group (A) & Group (B) & P-value \\
\hline Age (year) & $43.76 \pm 4.32$ & $45.12 \pm 3.98$ & 0.587 \\
\hline Gender (male/female) & $26 / 14$ & $24 / 16$ & 0.761 \\
\hline BMI $\left(\mathrm{kg} / \mathrm{m}^{2}\right)$ & $32.52 \pm 3.48$ & $31.19 \pm 4.23$ & 0.393 \\
\hline Duration of diabetes (years) & $11.32 \pm 4.77$ & $10.12 \pm 3.95$ & 0.241 \\
\hline HbA1c (\%) & $8.11 \pm 0.76$ & $7.85 \pm 0.91$ & 0.418 \\
\hline Systolic blood pressure (mmHg) & $138.37 \pm 10.31$ & $135.84 \pm 9.57$ & 0.926 \\
\hline Diastolic blood pressure (mmHg) & $81.24 \pm 7.41$ & $79.73 \pm 8.12$ & 0.872 \\
\hline High-density lipoprotein cholesterol (mg/dl) & $47.35 \pm 6.22$ & $48.65 \pm 7.16$ & 0.715 \\
\hline Low-density lipoprotein cholesterol (mg/dl) & $108.78 \pm 9.34$ & $106.92 \pm 8.51$ & 0.644 \\
\hline Triglycerides (mg/dl) & $146.82 \pm 12.15$ & $143.13 \pm 11.64$ & 0.615 \\
\hline
\end{tabular}

BMI: Body Mass Index; HBA1c: glycosylated hemoglobin

Table 2. Mean value and significance of ICAM-1, VCAM-1, tPA:Ag, E-selectin, HBA1c and HOMA-IR in group (A) before and after treatment.

\begin{tabular}{|c|c|c|c|c|}
\hline & \multicolumn{2}{|l|}{ Mean +SD } & \multirow[t]{2}{*}{ T-value } & \multirow[t]{2}{*}{ P-value } \\
\hline & Before & After & & \\
\hline ICAM-1 (ng/ml) & $95.87 \pm 8.16^{*}$ & $80.93 \pm 7.94$ & 9.15 & 0.002 \\
\hline VCAM-1 (ng /ml) & $828.33 \pm 36.42 *$ & $731.81 \pm 29.13$ & 10.61 & 0.001 \\
\hline E-selectin (ng/ml) & $15.18 \pm 4.12^{*}$ & $9.17 \pm 3.19$ & 8.21 & 0.003 \\
\hline t-PA antigen $(\mathrm{ng} / \mathrm{ml})$ & $7.11 \pm 1.87^{*}$ & $5.03 \pm 1.61$ & 7.84 & 0.005 \\
\hline HBA1c (\%) & $8.43 \pm 1.93^{*}$ & $7.24 \pm 1.72$ & 4.43 & 0.014 \\
\hline HOMA-IR & $4.52 \pm 1.75^{*}$ & $3.43 \pm 1.42$ & 3.92 & 0.025 \\
\hline
\end{tabular}

Table 3. Mean value and significance of ICAM-1, VCAM-1, tPA:Ag, E-selectin, HBA1c and HOMA-IR in group (B) before and at the end of the study.

\begin{tabular}{|c|c|c|c|c|}
\hline & \multicolumn{2}{|l|}{ Mean +SD } & \multirow[t]{2}{*}{ T-value } & \multirow[t]{2}{*}{ P-value } \\
\hline & Before & After & & \\
\hline ICAM-1 (ng/ml) & $94.31 \pm 7.56^{*}$ & $87.74 \pm 7.32$ & 5.19 & 0.021 \\
\hline VCAM-1 (ng /ml) & $824.93 \pm 37.81^{*}$ & $782.32 \pm 32.43$ & 6.14 & 0.015 \\
\hline E-selectin (ng/ml) & $14.72 \pm 4.54^{*}$ & $12.23 \pm 4.26$ & 4.13 & 0.026 \\
\hline t-PA antigen $(\mathrm{ng} / \mathrm{ml})$ & $6.94 \pm 1.59^{*}$ & $6.01 \pm 1.48$ & 3.75 & 0.038 \\
\hline HBA1c (\%) & $8.22 \pm 1.72 *$ & $6.14 \pm 1.63$ & 8.27 & 0.006 \\
\hline HOMA-IR & $4.11 \pm 1.63^{*}$ & $2.33 \pm 1.42$ & 7.62 & 0.009 \\
\hline
\end{tabular}


Table 4. Mean value and significance of ICAM-1, VCAM-1, tPA:Ag, E-selectin, HBA1c and HOMA-IR in group (A) and group (B) at the end of the study.

\begin{tabular}{|l|l|l|l|l|}
\hline \multicolumn{2}{|l|}{ Mean +SD } & T-value & P-value \\
\cline { 1 - 3 } & Before & After & & \\
\hline ICAM-1 $(\mathrm{ng} / \mathrm{ml})$ & $80.93 \pm 7.94^{*}$ & $87.74 \pm 7.32$ & 4.08 & 0.011 \\
\hline VCAM-1 $(\mathrm{ng} / \mathrm{ml})$ & $731.81 \pm 29.13^{*}$ & $782.32 \pm 32.43$ & 4.51 & 0.016 \\
\hline E-selectin $(\mathrm{ng} / \mathrm{ml})$ & $9.17 \pm 3.19^{*}$ & $12.23 \pm 4.26$ & 4.07 & 0.015 \\
\hline t-PA antigen(ng/ml) & $5.03 \pm 1.61^{*}$ & $6.01 \pm 1.48$ & 4.11 & 0.013 \\
\hline HBA1c $(\%)$ & $7.24 \pm 1.72^{*}$ & $6.14 \pm 1.63$ & 3.68 & 0.027 \\
\hline HOMA-IR & $3.43 \pm 1.42^{*}$ & $2.33 \pm 1.42$ & 3.57 & 0.028 \\
\hline
\end{tabular}

ICAM-1: Inter-Cellular Adhesion Molecule; VCAM-1: Vascular Cell Adhesion Molecule; HBAlc:glycosylated hemoglobin; HOMAIR:Homeostasis Model Assessment-Insulin Resistance Index; tPA:Ag: tissue Plasminogen Activator Antigen; $\left(^{\star}\right)$ indicates a significant difference between the two groups, $\mathrm{P}<0.05$.

ICAM-1:Inter-Cellular Adhesion Molecule; VCAM-1: Vascular Cell Adhesion Molecule; HBAlc:glycosylated hemoglobin; HOMAIR:Homeostasis Model Assessment-Insulin Resistance Index; tPA:Ag: tissue Plasminogen Activator Antigen; ${ }^{*}$ ) indicates a significant difference between the two groups, $\mathrm{P}<0.05$.

ICAM-1:Inter-Cellular Adhesion Molecule; VCAM-1: Vascular Cell Adhesion Molecule; HBAlc:glycosylated hemoglobin; HOMAIR:Homeostasis Model Assessment-Insulin Resistance Index; tPA:Ag: tissue Plasminogen Activator Antigen; $\left.{ }^{*}\right)$ indicates a significant difference between the two groups, $\mathrm{P}<0.05$.

\section{Discussion}

Diabetes-related costs are projected to double in the next 25 years, leading to a significant increase in the economic burden for patients and for healthcare systems [26]. Exercise is recognized as a cornerstone for type 2 diabetes mellitus (T2DM) prevention and treatment due to its ability to regulate blood sugar levels, with minimal undesired side effects [27]. Along with glycemic control and improving endothelial function [28]. Despite these general benefits there is a gap in the knowledge regarding the best exercise intervention in order to achieve maximal enhancements with lowest risks, such that exercise can be used in a primary care recommendation [29].

The main finding of the present study was the fact that patients with type 2 diabetes mellitus have a significantly accentuated insulin resistance and abnormal endothelial function. Physical exercise training also improved the glycemic profile and markers of endothelial function. Resistance exercise appears to be more beneficial than aerobic exercise for improving insulin resistance in T2DM. Also, aerobic exercise appears to be more beneficial than resistance exercise for improving endothelial function in T2DM.

Nassis et al., proved that 12 weeks of aerobic training improved insulin sensitivity in overweight and obese girls [30]. Similarly, moderate to heavy-intensity aerobic training (i.e., $60 \%-95 \%$ of maximal heart rate) that was done 3 times a week for 6 months was shown to improve insulin sensitivity in both younger $(n=14$; mean [SD] age, 29.1 [4.6] years) and older ( $n=8$; mean [SD] age, 62.3 [4.7] years) women [31]. Duncan et al demonstrated that 30 minutes of walking exercise 3 to 7 days per week for 6 months--reversed the prediabetic state of individuals without a change in their diets or any loss of body weight [32]. Also, In 8 healthy young men, 18 to 25 years of age, 6 weeks of moderate-intensity cycling performed for 1 hour 5 days a week was capable of increasing their insulin sensitivity and glucose effectiveness [33]. lbaftez et al., conducted a study of twice-weekly progressive resistance training for 16 weeks by 10 older men with newly diagnosed T2DM resulted in a $46.3 \%$ increase in insulin sensitivity, along with a $7.1 \%$ reduction in fasting glycemia and a significant loss of visceral fat [34]. Dunstan et a1, showed that 18 men with T2DM aged 60 to 80 years successfully progressed over 6 months of resistance training to completing 3 sets of 8 to 10 repetitions done at $75 \%$ to $80 \%$ of maximal on 8 to 10 exercises thrice weekly [35].

The glycemic effects of resistance versus aerobic exercise must be considered. In non-obese, young women (18-35 years of age), 6 months of either aerobic or resistance training improved muscular glucose disposal by different mechanisms [36]. While aerobic exercise training done by individuals with T2DM increases the levels of glucose transporter 4 (GLUT4) in trained muscle, along with insulin receptors, protein kinase B, glycogen synthase (GS), and GS total activity after acute training [37]. While, an increase in their amount of fat-free mass (FFM) from resistance training contributed to glucose uptake from a mass effect without altering the intrinsic capacity of muscle to respond to insulin; conversely, aerobic training enhanced insulin sensitivity independently of changes in FFM or maximal aerobic capacity [38]. So, resistance training is recommended for patients with T2DM because it has the potential to improve muscular strength and endurance, enhance flexibility, improve body composition, and decrease risk for cardiovascular disease, all while increasing amounts of insulinsensitive muscle mass $[39,40]$ as Skeletal muscle accounts for up to $80 \%$ of glucose disposal following ingestion or infusion, whereas adipose tissue only accounts for 3-4\% of insulin mediated glucose uptake [41].

Physical training also appears to enhance $\beta$-cell insulin production in individuals with T2DM as long as adequate amounts of functioning $\beta$-cells remain in the pancreas, also regular exercise apparently enhances the suppression of tumor narcosis factor-alpha (TNF- $\alpha$ ) and thereby offers protection against any insulin resistance [42].

In this study, improvement in endothelial cell function was noticed as a result of aerobic and resistance exercise. Also, aerobic exercise appears to be more beneficial than resistance exercise for improving endothelial function in T2DM. In line with our data, Zoppini et al., demonstrated that vascular endothelial cell function improved in obese T2DM subjects who performed aerobic exercise for 6 months (50\% to $70 \%$ heart rate reserve, 60 minutes/session, 2 times per week) [43]. Also, Hamdy et al. performed a 6-month study on T2DM subjects with impaired glucose tolerance in which participants performed aerobic exercise $(60 \%$ to $80 \%$ HRmax, 30 minutes, 3 times per week, or at least 150 minutes per week) and reported a significant improvement in endothelial cell function [44]. Also, da Silva etal., conducted a study of highly intensity aerobic exercise of $80 \%$ maximum heart rate versus $55 \%$ of maximum heart rate for a duration of 6 weeks and concluded that high intensity aerobic training improved the functional capability and endothelium-dependent vasodilator response in patients with metabolic syndrome and type 2 diabetes mellitus [8]. The current study had a higher frequency of aerobic exercise per week than the study conducted by Zoppini et al., and the exercise periods and overall frequency were higher than in the study performed by Hamdy et al. Despite our short study period (12 weeks), the exercise programs appear to have had an effect on vascular endothelial cell function. When we examine studies where no change in endothelial cell function was observed, such as the 10-week aerobic exercise study performed by Ostergard et al., [45], we note that their study period was shorter than the current study, and that the exercise was less frequent. 
In line with our results, Kwon etal., conducted a study on 40 overweight Korean women with T2DM and were assigned into 3 groups: an aerobic exercise group, resistance exercise group and control group, 60 minutes per day, 5 days per week for 12 weeks and assessed endothelial function by flow-mediated dilation (FMD) and found that aerobic exercise appears to be more beneficial than resistance exercise for improving endothelial function in T2DM [46]. Also, Okada et al. found endothelial function improvement in 38 diabetic subjects after practicing aerobic physical exercise with resistance, independently of glycemic control and increased insulin sensitivity [47]. Although Cohen et al., conducted a resistance exercise study on obese T2DM subjects in which progressive resistance exercise (75\% to $85 \% 1 \mathrm{RM}$, 3 sets, 8 reps) was employed. No significant change in endothelial cell function was observed after 2 months; however, after 14 months they reported an improvement in endothelial cell function [48]. The resistance exercises in the current study were $50 \%$ to $60 \%$ of onerepetition maximum (1RM) with a work range of two sets of 10 to 15 repetitions. Subjects then progressed from $65 \%$ to $75 \%$ of $1 \mathrm{RM}$ at a work range of six to eight repetitions (two sets) and remained at this level until the end of the program, and resulted in some improvement to endothelial cell function; however, we feel that the duration of the study was too short to yield statistically significant changes. Thus, due to the short duration of this exercise study, aerobic exercise was more effective than resistance exercise in improving endothelial cell function.

Explanation for the endothelial function improvement could be the changes in the lipid profile after aerobic physical exercise training, specifically low density lipoprotein (LDL) cholesterol. The LDL cholesterol had a significant improvement as an effect of low and of high intensity aerobic physical exercise in the present study. Other studies showed that the improvement in lipids profile is associated with vascular function improvement [49]. This is particularly important in diabetic patients and in those with cardiovascular risk factors (metabolic syndrome). The oxidation of LDL interferes with the nitric oxide (NO) formation. The decrease in LDL cholesterol post physical exercise training can have contributed to increase NO bioavailability, which improves endothelium-dependent vasodilation and as a result endothelial function improvement [50,51].

The current study has important strengths and limitations. The major strength is the supervised nature of the study. Supervising physical activity removes the need to question compliance or to rely on activity questionnaires. Further, all exercise sessions were supervised and adherence to the activities was essentially $100 \%$. Also, our study has a strength point as a large number of subjects leading to excellent statistical power to detect exercise exposure effects across groups. Moreover, the study was randomized; hence, we can extrapolate adherence to the general population. In the other hand, the major limitations is that this study did not include a control group. Finally, within the limit of this study, resistance exercise training is recommended for improving insulin resistance and aerobic exercise training is recommended for modulation of endothelial function in patients with type 2 diabetes mellitus. Further researches are needed to explore the impact of different exercise training techniques on quality of life and other biochemical parameters among patients with type 2 diabetes mellitus.

\section{Conclusion}

Based on our findings, resistance exercise appears to be more beneficial than aerobic exercise for improving insulin resistance in type 2 diabetes mellitus. Also, aerobic exercise appears to be more beneficial than resistance exercise for improving endothelial function in type 2 diabetes mellitus.

\section{Acknowledgment}

This project was funded by the Deanship of Scientific Research (DSR), King Abdulaziz University, Jeddah, under grant no. (26-1421436). The authors, therefore, acknowledge with thanks DSR technical and financial support.

\section{References}

1. International Diabetes Federation. Diabetes atlas. 5th ed. Brussels, Belgium: IDF 2011

2. Oliveira C, Simões M, Carvalho J, Ribeiro J (2012) Combined exercise for people with type 2 diabetes mellitus: a systematic review. Diabetes Res Clin Pract 98: 187-198. [Crossref]

3. Danaei G, Finucane MM, Lu Y, Singh GM, Cowan MJ, et al. (2011) National, regional, and global trends in fasting plasma glucose and diabetes prevalence since 1980: systematic analysis of health examination surveys and epidemiological studies with 370 country-years and 2.7 million participants. Lancet 378: 31-40.

4. Booth GL, Kapral MK, Fung K, Tu JV (2006) Relation between age and cardiovascular disease in men and women with diabetes compared with non-diabetic people: a population-based retrospective cohort study. Lancet 368: 29-36. [Crossref]

5. Fornengo P, Bosio A, Epifani G, Pallisco O, Mancuso A, et al. (2006) Prevalence of silent myocardial ischaemia in new-onset middle-aged Type 2 diabetic patients without other cardiovascular risk factors. Diabet Med 23: 775-779.

6. Lavrencic A, Salobir B, Keber I (2000) Physical training improves flow-mediated dilation in patients with the poly-metabolic syndrome. Arterioscler Thromb Vasc Biol 20: 551-555.

7. Maiorana A, O’Driscoll G, Cheetham C, Dembo L, Stanton K, et al. (2001) The effect of combined aerobic and resistance exercise training on vascular function in type 2 diabetes. J Am Coll Cardiol 38: 860-866. [Crossref]

8. da Silva CA, Ribeiro JP, Canto JC, da Silva RE, Silva Junior GB, et al. (2012) Highintensity aerobic training improves endothelium-dependent vasodilation in patients with metabolic syndrome and type 2 diabetes mellitus. Diabetes Res Clin Pract 95: 237-245. [Crossref]

9. Perticone F, Ceravolo R, Pujia A, Ventura G, Iacopino S, et al. (2001) Prognostic significance of endothelial dysfunction in hypertensive patients. Circulation 104: 191196.

10. Sonne M, Scheede-Bergdahl C, Olsen D, Højbjerre L, Alibegovic A, et al. (2007) Source Effects of physical training on endothelial function and limb blood flow in type 2 diabetes. Appl Physiol Nutr Metab 32: 936-41.

11. Moien-Afshari F1, Ghosh S, Elmi S, Rahman MM, Sallam N, et al. (2008) Exercise restores endothelial function independently of weight loss or hyperglycaemic status in db/db mice. Diabetologia 51: 1327-1337. [Crossref]

12. Deanfield JE, Halcox JP, Rabelink TJ (2007) Endothelial function and dysfunction: testing and clinical relevance. Circulation 115: 1285-1295. [Crossref]

13. Blankenberg S, Barbaux S, Tiret L (2003) Adhesion molecules and atherosclerosis Atherosclerosis 170: 191-203. [Crossref]

14. Jansson J, Nilsson T, Johnson OV (1998) Willebrand factor, tissue plasminogen activator, and dehydroepiandrosterone sulphate predict cardiovascular death in a 10 year follow up of survivors of acute myocardial infarction. Heart 80: 334-337.

15. Reaven GM (1988) Banting lecture 1988. Role of insulin resistance in human disease. Diabetes 37: 1595-1607. [Crossref]

16. Kraus W, Torgan C, Duscha B (2001) Studies of a targeted risk reduction intervention through defined exercise (STRRIDE). Med Sci Sports Exerc 33:1774-1784.

17. Tanasescu M, Leitzmann MF, Rimm EB, Hu FB (2003) Physical activity in relation to cardiovascular disease and total mortality among men with type 2 diabetes. Circulation 107: 2435-2439. [Crossref]

18. Mayer-Davis E, D’Agostino Jr R, Karter A (1998) Intensity and amount of physical activity in relation to insulin sensitivity: the Insulin Resistance Atherosclerosis Study. JAMA 279: 669-674.

19. Smutok M, Reece C, Kokkinos P, Farmer C, Dawson P, et al. (1994) Effects of exercise training modality on glucose tolerance in men with abnormal glucose regulation. Int $J$ Sports Med 15: 283-289. 
20. Chodzko-Zajko WJ, Proctor DN, Fiatarone Singh MA, Minson CT, Nigg CR, (1998) Exercise and physical activity for older adults. Med Sci Sports Exerc 30: 992-1008. [Crossref]

21. Jakovljevic B, Donovan G, Nunan D, McDonagh S, Trenell M, et al. (2010) The effect of aerobic versus resistance exercise training on peak cardiac power output and physical functional capacity in patients with chronic heart failure. Int J Cardiol 145: 526-528.

22. Jørgensen J, Bech-Pedersen D, Zeeman P, Sørensen J, Andersen L, et al. (2010) Effect of intensive outpatient physical training on gait performance and cardiovascular health in people with hemiparesis after stroke. Phys Ther 90: 527-537.

23. Yang J, Park Y, Zhang H, Xu X, Laine G, et al. (2009) Feed-forward signaling of TNF-a and NF-?B via IKK- $\beta$ pathway contributes to insulin resistance and coronary arteriolar dysfunction in type 2 diabetic mice. Am J Physiol Heart Circ Physiol 296: H1850H1858.

24. Tanaka H, Monahan KD, Seals DR (2001) Age-predicted maximal heart rate revisited. J Am Coll Cardiol 37: 153-156. [Crossref]

25. Lucotti P, Monti L, Setola E, Galluccio E, Gatti R, et al. (2011) Aerobic and resistance training effects compared to aerobic training alone in obese type 2 diabetic patients on diet treatment. Diabetes Res Clin Pract 94: 395-403.

26. Huang ES, Basu A, O'Grady M, Capretta JC (2009) Projecting the future diabetes population size and related costs for the U.S. Diabetes Care 32: 2225-2229. [Crossref]

27. Colberg S, Sigal R, Fernhall B, Regensteiner J, Blissmer B, et al. (2010) Chasan-Taber L, Albright A, Braun B, American College of Sports Medicine; American Diabetes Association. Exercise and type 2 diabetes: the American College of Sports Medicine and the American Diabetes Association: joint position statement executive summary. Diabetes Care 33: 2692-2696.

28. Hambrecht R, Wolf A, Gielen S, Linke A, Hofer J, et al. (2000) Effect of exercise on coronary endothelial function in patients with coronary artery disease. $N$ Engl $\mathrm{J}$ Med 342: 454-460. [Crossref]

29. Beckman TJ (2004) Prescribing exercise: is your physician's head in the game? Arch Intern Med 164: 2066-2067. [Crossref]

30. Nassis G, Papantakou K, Skenderi K, Triandafillopoulou M, Kavouras S, et al. (2005) Aerobic exercise training improves insulin sensitivity without changes in body weight, body fat, adiponectin, and inflammatory markers in overweight and obese girls. Metabolism 54: 1472-1479.

31. Goulet E, Melancon M, Aubertin-Leheudre M, Dionne U (2005) Aerobic training improves insulin sensitivity $72-120 \mathrm{~h}$ after the last exercise session in younger but not in older women. Eur J Appl PhysioL 95: 146-152.

32. Duncan G, Perri M, Theriaque D, Hutson A, Eckel R, et al. (2003) Exercise training without weight loss, increases insulin sensitivity and postheparin plasma lipase activity in previously sedentary adults. Diabetes Care 26: 557-562.

33. Nishida Y, Higaki Y, Tokuyama K, Fujimi K, Kiyonaga A, et al. (2001) Effect of mild exercise training on glucose effectiveness in healthy men. Diabetes Care 24: 10081013. [Crossref]

34. Ibañez J, Izquierdo M, Argüelles I, Forga L, Larrión J, et al. (2005) Twice-weekly progressive resistance training decreases abdominal fat and improves insulin sensitivity in older men with type 2 diabetes. Diabetes Care 28: 662-667.

35. Dunstan D, Daly R, Owen N, Jolley D, De Courten M, et al. (2002) High-intensity resistance training improves glycemic control in older patients with type 2 diabetes. Diabetes Care 25: 1729-1736.
36. Poehlman E, Dvorak R, DeNino W, Brochu M, Ades P (2000) Effects of resistance training and endurance lraining on insulin sensitivity in nonobese,young women: A controlled randomized trial. J Cfin Endocrinol Metabol 85: 2463-2468.

37. Holten M, Zacho M, Gaster M, Juel C, Wojtaszewski J, et al. (2004) Strength lraining increases insulin-mediated glucose uptake, GLUT4 content, and insulin signaling in skeletal muscle in patients with lype 2 diabetes. Diabetes 53: 294-305.

38. Sigal RJ, Kenny GP, Wasserman DH, Castaneda-Sceppa C (2004) Physical activity/ exercise and type 2 diabetes. Diabetes Care 27: 2518-2539. [Crossref]

39. Ishii T, Yamakita T, Sato T, Tanaka S, Fujii S (1998) Resistance training improves insulin sensitivity in NIDDM subjects without altering maximal oxygen uptake. Diabetes Care 21: 1353-1355.

40. Ferrara CM, McCrone SH, Brendle D, Ryan AS, Goldberg AP (2004) Metabolic effects of the addition of resistive to aerobic exercise in older men. Int $J$ Sport Nutr Exerc Metab 14: 73-80. [Crossref]

41. DeFronzo RA, Gunnarsson R, Björkman O, Olsson M, Wahren J (1985) Effects of insulin on peripheral and splanchnic glucose metabolism in noninsulin-dependent (type II) diabetes mellitus. J Clin Invest 76: 149-155. [Crossref]

42. Dela F, von Linstow ME, Mikines KJ, Galbo H (2004) Physical training may enhance beta-cell function in type 2 diabetes. Am J Physiol Endocrinol Metab 287: E1024-1031. [Crossref]

43. Zoppini G, Targher G, Zamboni C, Venturi C, Cacciatori V, et al. (2006) Effects of moderate-intensity exercise training on plasma biomarkers of inflammation and endothelial dysfunction in older patients with type 2 diabetes. Nutr Metab Cardiovasc Dis 16: 543-549.

44. Hamdy O, Ledbury S, Mullooly C, Jarema C, Porter S, et al. (2003) Lifestyle modification improves endothelial function in obese subjects with the insulin resistance syndrome. Diabetes Care 26: 2119-2125.

45. Middlebrooke AR, Elston LM, Macleod KM, Mawson DM, Ball CI, et al. (2006) Six months of aerobic exercise does not improve microvascular function in type 2 diabetes mellitus. Diabetologia 49: 2263-2271. [Crossref]

46. Kwon H, Min K, Ahn H, Seok H, Lee J, et al. (2011) Effects of Aerobic Exercise vs Resistance Training on Endothelial Function in Women with Type 2 Diabetes Mellitus. Diabetes Metab J 35: 364-373.

47. Cohen N, Dunstan D, Robinson C, Vulikh E, Zimmet P, et al. (2008) Improved endothelial function following a 14-month resistance exercise training program in adults with type 2 diabetes. Diabetes Res Clin Pract 79: 405-411.

48. Sheu WH, Chen YT, Lee WJ (2001) Improvement in endothelial dysfunction with LDL cholesterol level $<80 \mathrm{mg} / \mathrm{dl}$ in type 2 diabetic patients. Diabetes Care 24: 1499-1501. [Crossref]

49. Kugiyama K, Kerns SA, Morrisett JD, Roberts R, Henry PD (1990) Impairment of endothelium-dependent arterial relaxation by lysolecithin in modified low-density lipoproteins. Nature 344: 160-162. [Crossref]

50. Chin JH, Azhar S, Hoffman BB (1992) Inactivation of endothelial derived relaxing factor by oxidized lipoproteins. J Clin Invest 89: 10-18. [Crossref]

51. Okada S, Hiuge A, Makino H, Nagumo A, Takaki H, et al. (2010) Effect of exercise intervention on endothelial function and incidence of cardiovascular disease in patients with type 2 diabetes. J Atheroscl Thromb 17: 828-833.

Copyright: $@ 2017$ El-Kader SMA. This is an open-access article distributed under the terms of the Creative Commons Attribution License, which permits unrestricted use, distribution, and reproduction in any medium, provided the original author and source are credited. 